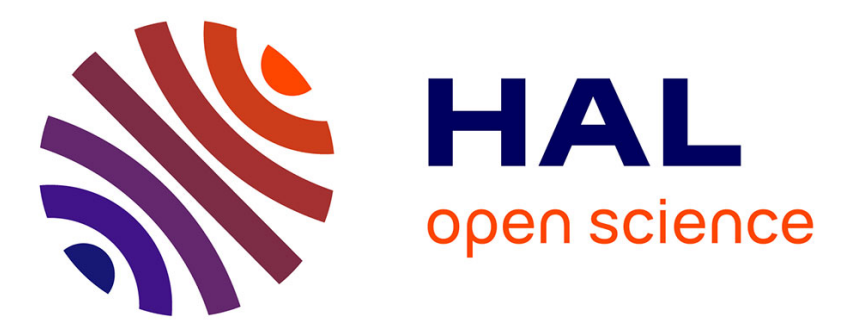

\title{
Endothelium-dependent adaptation of arterial wall viscosity during blood flow increase is impaired in essential hypertension
}

Frederic Roca, Jeremy Bellien, Michele Iacob, Robinson Joannides

\section{- To cite this version:}

Frederic Roca, Jeremy Bellien, Michele Iacob, Robinson Joannides. Endothelium-dependent adaptation of arterial wall viscosity during blood flow increase is impaired in essential hypertension. Atherosclerosis, 2019, 285, pp.102 - 107. 10.1016/j.atherosclerosis.2019.04.208 . hal-03480694

\section{HAL Id: hal-03480694 \\ https://hal.science/hal-03480694}

Submitted on 20 Dec 2021

HAL is a multi-disciplinary open access archive for the deposit and dissemination of scientific research documents, whether they are published or not. The documents may come from teaching and research institutions in France or abroad, or from public or private research centers.
L'archive ouverte pluridisciplinaire HAL, est destinée au dépôt et à la diffusion de documents scientifiques de niveau recherche, publiés ou non, émanant des établissements d'enseignement et de recherche français ou étrangers, des laboratoires publics ou privés.

\section{(ㄷ)(1) $\$$}

Distributed under a Creative Commons Attribution - NonCommerciall 4.0 International 
Endothelium-dependent adaptation of arterial wall viscosity during blood flow increase is impaired in essential hypertension

Frederic Roca ${ }^{1,2,3,4}$, Jeremy Bellien ${ }^{1,2,3,4}$, Michele Iacob $^{1,2}$, Robinson Joannides ${ }^{1,2,3,4}$

${ }^{1}$ Rouen University Hospital, Department of Pharmacology, F 76000 Rouen, France

2 Normandie Univ, UNIROUEN, Inserm U1096, F 76000, Rouen, France

${ }^{3}$ University of Rouen, Institute for Research and Innovation in Biomedicine, Rouen, France.

4 Clinical Investigation Center CIC-CRB 1404, Rouen University Hospital, Rouen, France

Corresponding author: Frédéric Roca, Service de Pharmacologie, Inserm U1096,

CHU de Rouen, 76031 Rouen Cedex, France. Tel: +33 2328890 30, Fax: +33 23288

91 16; Email: frederic.roca@chu-rouen.fr 


\section{ABSTRACT}

Background and aims: Arterial wall viscosity (AWV) is regulated by endotheliumderived NO and epoxyeicosatrienoic acids (EETs) under baseline physiological conditions. Whether these factors regulate AWV during blood flow increase and whether this mechanism is affected in essential hypertensive patients (HT) remain unknown.

Methods: The evolution of radial artery diameter, wall thickness and arterial pressure in response to an increase in flow induced by hand skin heating were measured in 18 untreated HT and 14 normotensive controls (NT) during local infusion of saline and the respective pharmacological inhibitors of NO-synthase and EETs synthesis by cytochrome P450, L-NMMA and/or fluconazole. AWV was estimated by the ratio of the viscous energy dissipated $\left(\mathrm{W}_{\mathrm{V}}\right)$ to the elastic energy stored $\left(\mathrm{W}_{\mathrm{E}}\right)$ obtained from the pressure-diameter relationship. Concomitant changes in operating conditions, which influence the AWV, were taken into account by calculating the midwall stress.

Results: Baseline $\mathrm{W}_{\mathrm{V}}$ and $\mathrm{W}_{\mathrm{E}}$ were higher in $\mathrm{HT}$ than in $\mathrm{NT}$ but $\mathrm{W}_{\mathrm{V}} / \mathrm{W}_{\mathrm{E}}$ was similar. In saline condition, $\mathrm{W}_{\mathrm{V}} / \mathrm{W}_{\mathrm{E}}$ increased in $\mathrm{HT}$ during heating but not in NT. In the presence of L-NMMA and/or fluconazole, $\mathrm{W}_{\mathrm{V}} / \mathrm{W}_{\mathrm{E}}$ increased during heating in NT. In contrast, these inhibitors did not modify the increase in $\mathrm{W}_{\mathrm{V}} / \mathrm{W}_{\mathrm{E}}$ during heating in HT compared to saline. In all conditions, a larger increase in $\mathrm{W}_{\mathrm{V}}$ than $\mathrm{W}_{\mathrm{E}}$ was responsible for the increase in $\mathrm{W}_{\mathrm{V}} / \mathrm{W}_{\mathrm{E}}$.

Conclusions: The release of NO and EETs maintains a stable AWV during flow increase and this endothelial adaptive regulation is lost during essential hypertension, which may promote excessive viscous energy dissipation and cardiovascular 
uncoupling. Restoration of EETs availability with inhibitors of soluble epoxide hydrolase could thus constitute a promising pharmacological approach to restore the endothelial adaptive regulation of AWV.

Keywords: arterial wall viscosity, endothelium, nitric oxide, epoxyeicosatrienoic acids, hypertension, endothelial dysfunction 


\section{INTRODUCTION}

Arterial wall viscosity (AWV) is a physiological phenomenon that takes part in the control of cardiac energy dissipation along the arterial tree. Thus, in viscoelastic conduit arteries, elastic energy $\left(\mathrm{W}_{\mathrm{E}}\right)$, stored during the loading phase of each beat, is not fully restored during the unloading phase. This results in a hysteresis loop of the artery pressure-diameter relationship whose area has an energy dimension and corresponds to the viscous energy dissipated $\left(\mathrm{W}_{\mathrm{V}}\right)$ as heat during each cycle. Thereby, AWV can be expressed as an absolute value of $\mathrm{W}_{\mathrm{V}}$ or as a percentage of the $\mathrm{W}_{\mathrm{E}}$ stored within the arterial wall $\left(\mathrm{W}_{\mathrm{V}} / \mathrm{W}_{\mathrm{E}}\right)$. AWV notably depends on the passive viscous properties of the smooth muscle layer components, the smooth muscle tone and the operating conditions that determine the magnitude of $\mathrm{W}_{\mathrm{E}}, \mathrm{W}_{\mathrm{V}}$ and $\mathrm{W}_{\mathrm{V}} / \mathrm{W}_{\mathrm{E}}$, which increase with midwall stress $[1-4]$.

In addition, we recently demonstrated that NO and the lipid mediators produced by endothelial cytochrome P450, epoxyeicosatrienoic acids (EETs), regulate AWV in young healthy humans through tone-dependent and -independent mechanisms [1]. These results were obtained under basal condition, but it is not known whether an adaptation of AWV occurs during situation of increase in flow to adjust energy dissipation and maintain an adequate blood flow propagation, and whether the endothelium plays a role in this adaptation. Moreover, given that the conduit artery endothelial dysfunction in essential hypertension is notably due to the decrease in the bioavailability of NO and EETs, this may affect AWV adaptation and thus cardiovascular coupling [5-7]. In these conditions, the limitation of energy dissipation 
along the arterial tree could constitute a new physiological dimension in cardiovascular coupling and open the door for the pharmacological modulation of endothelial factors. The objective of the present study was thus to assess, using a functional approach based on local infusion of pharmacological inhibitors, the role of endothelium-derived NO and EETs in the regulation of AWV during increase in blood flow and to assess the impact of essential hypertension on this regulation. 


\section{MATERIALS AND METHODS}

\section{Subjects}

18 untreated hypertensive subjects (HT) and 14 normotensive controls (NT) participated to this control study. All subjects were nonsmokers, must not have received hormone replacement therapies or statins for the last 6 months, and did not receive any medication at the time of the study. Subjects with cardiac and/or cerebrovascular ischemic disease, heart failure, impaired renal function (estimated glomerular filtration rate lower than $60 \mathrm{~mL} / \mathrm{min}$ according to the Cockcroft-Gault equation), or other major pathologies were excluded from the study. Secondary forms of hypertension were excluded by routine diagnostic procedures. HT subjects were enrolled if never treated or reporting a medical history of discontinued pharmacological antihypertensive treatment interrupted for at least 3 months before the day of inclusion to exclude possible remnant effects of the drugs on endothelial function. NT controls were frequency-matched on age, sex ratio, body mass index and major vascular risk factors. The study was approved by the local Ethics Committee (Committee for the Protection of Persons of Nord-Ouest I), and all participants gave written informed consent. The study was conducted according with the Principles of Good Clinical Practice and the Declaration of Helsinki and was registered at https://www.eudract.ema.europa.eu under the unique identifier RCB2007-A001-10-53.

\section{General procedure}

Measurements were performed in the morning while subjects were in a supine position, in a quiet air-conditioned room, maintained at a constant temperature $\left(22^{\circ} \mathrm{C}\right.$ to $\left.24^{\circ} \mathrm{C}\right)$. 
Radial artery internal diameter (d), wall thickness, blood flow (Q) and digital arterial pressure were continuously obtained using a high-precision echotracking device coupled to a Doppler system (NIUS 02, Asulab) and a finger photoplethysmograph (Finapres System, Ohmeda) as previously described [1,6,8-10]. Briefly, these devices allow the measurement of radial artery internal diameter with a resolution on the diameter evolution of less than $1 \mu \mathrm{m}$ and of blood pressure with a precision of $2 \mathrm{mmHg}$ [11]. Pressure measurements were performed similarly before and after blood flow increase in accordance with previous results showing that the finger pressure waveform and its relationship with the radial pressure waveform are poorly affected by local changes in tone [12-15]. Increase in blood flow was obtained by progressive hand skin heating (from $34^{\circ} \mathrm{C}$ to $44^{\circ} \mathrm{C}$ ) as previously described [6]. Total blood viscosity was measured with a cone-plate viscometer (Ex100 CTB, Brookfield) at a shear rate of 241 $\mathrm{s}^{-1}$ at $37^{\circ} \mathrm{C}$ and the mean arterial wall shear stress was calculated on the basis of a Poiseuillean model as $\tau=\left[(4 \mu \mathrm{Q}) /\left(\pi \mathrm{r}^{3}\right),(\mathrm{r}=\mathrm{d} / 2)\right][6,16]$. The midwall stress $(\sigma)$, which characterizes the operating conditions related to pressure and arterial geometry, was calculated as $\sigma=2 . \mathrm{MBP}\left(\mathrm{r}_{\mathrm{i}} \cdot \mathrm{r}_{\mathrm{e}} / \mathrm{r}\right)^{2} /\left(\mathrm{re}_{\mathrm{e}}^{2}-\mathrm{r}_{\mathrm{i}}^{2}\right)$, where MBP is mean blood pressure, $\mathrm{r}_{\mathrm{i}}$ and $\mathrm{r}_{\mathrm{e}}$ are the internal and external radii, respectively, and $r$ the radius at the midwall as $r=\left(r_{i}+r_{e}\right) / 2$ $[8,17]$.

\section{Pharmacological inhibitors}

The forearm volume of each volunteer was measured by the water displacement method to adjust the doses of the pharmacological agents to be infused. The NO-synthase inhibitor $\mathrm{N}^{\mathrm{G}}$-monomethyl-L-arginine (L-NMMA) (Bachem), the inhibitor of cytochrome P450 fluconazole (Pfizer Holding), and L-NMMA associated with 
fluconazole, were used to assess the role of endothelium-derived NO and EETs in the regulation of AWV as previously described [18]. Briefly, a 27-gauge needle was inserted under local anesthesia ( $1 \%$ lidocaine) into the brachial artery of the nondominant arm to permit the continuous infusion of saline $(0.9 \%)$ or inhibitors during the entire heating procedure. To obtain high cumulative doses and to compensate for the diluting effect of the increase in flow during heating (from 10 to $50 \mathrm{~mL} / \mathrm{min}$ in control conditions), we increased the dose of inhibitors between $34^{\circ} \mathrm{C}$ and $44^{\circ} \mathrm{C}$ [9]. Therefore, the starting dose of L-NMMA of $8 \mu \mathrm{mol} / \mathrm{min}$ per liter was infused during 8 minutes at $34^{\circ} \mathrm{C}$ and $20 \mu \mathrm{mol} / \mathrm{min}$ per liter at $44^{\circ} \mathrm{C}$ [18]. Similarly, fluconazole was infused at a dose of $0.4 \mu \mathrm{mol} / \mathrm{min}$ per liter at $34^{\circ} \mathrm{C}$ and $1.6 \mu \mathrm{mol} / \mathrm{min}$ per liter at $44^{\circ} \mathrm{C}$ [18].

\section{Measurement of AWV}

AWV was estimated from the pressure-diameter relationship as previously described $[1,4,19,20]$. $\mathrm{W}_{\mathrm{E}}$ was assessed for each cardiac cycle by integrating the pressure-diameter area during the loading phase i.e., from diastolic to systolic pressure, and is thus graphically, bounded by the area under the pressure-diameter relationship, the pulse pressure and the pulse diameter (Supplementary figure 1). The area of the hysteresis loop of the pressure-diameter relationship obtained during the loading and unloading phases, which has similarly a dimension of energy, corresponds in fact to the energy dissipated in viscous work $\left(\mathrm{W}_{\mathrm{V}}\right)$ by the arterial wall during one cardiac cycle. The loop area was measured by image analysis software (ImageJ). Energies are expressed in joules per square meters during one cycle. AWV is expressed either in absolute value of $\mathrm{W}_{\mathrm{V}}$ or as a percentage of the energy stored during the loading phase (relative viscosity $=$ $\left.\mathrm{W}_{\mathrm{V}} / \mathrm{W}_{\mathrm{E}} .100\right)[1,19,21,22]$. The calculation of hysteresis was made after the temporal 
synchronization of the feet of pressure and diameter waves (Supplementary figure 2A and $2 \mathrm{~B}$ ). These waveforms were synchronized manually after defining the feet of the wave as the minimal values of pressure and diameter just before the ascending phase of each cycle. Feet synchronization resulted in the graphical superposition of the two upshot phases as previously described $[1,23]$. Data presented for AWV was the average of at least 3 cardiac cycles. Coefficient of variation of the measure of relative viscosity by this method was $11.6 \%$ based on preliminary results.

\section{Statistical analysis}

Statistics were performed using the SYSTAT package (SYSTAT 8.0; SPSS). Qualitative variables are presented as absolute and relative frequencies. Continuous variables are presented in the text and table as median [interquartile range, IQR 25-75] or mean $\pm \mathrm{SD}$ according to data normality and mean $\pm \mathrm{SEM}$ in figures. Previous studies suggest a similar baseline relative viscosity between NT and HT [24]. Based on our previous results observed after inhibition with L-NMMA and fluconazole at baseline in young healthy subjects (32.2\% increase of relative viscosity), we hypothesize a $30 \%$ increase in relative viscosity in HT subjects with endothelial dysfunction after heating [1]. Consequently, the sample size was estimated at 14 subjects per group for a $5 \% \alpha$ risk and a power 1- $\beta$ at $90 \%$. Comparisons between NT and HT baseline characteristics were performed using a Student $t$ test or a Mann-Whitney test as appropriate. The effect of hand skin heating on the radial artery parameters was assessed using a General Linear Model including subjects, inhibitors (including saline) and group as factors. In case of significant hand skin heating effect, inhibitors effect, group effect or interaction, this analyze was followed by single comparisons: 1) the evaluation of the effect of hand skin 
heating, for each sequence of inhibition, on radial artery parameters, in NT and HT, with a paired t test or Wilcoxon matched-pairs signed rank test as appropriate; 2) in each sequence of inhibition, the comparison of changes in radial artery parameters after hand skin heating between NT and HT was evaluated with a Student $\mathrm{t}$ test or a MannWhitney test as appropriate; 3) the comparison of the effect of inhibitors versus saline in NT and HT groups was evaluated by a paired t test or Wilcoxon matched-pairs signed rank test as appropriate. Results of the single comparisons are presented in tables and figures, and only the General Linear Model results about the main outcome $\left(\mathrm{W}_{\mathrm{V}} / \mathrm{W}_{\mathrm{E}}\right.$ ratio), is presented in the text to simplify the results section. Finally, variations of $\mathrm{W}_{\mathrm{E}}$ and $\mathrm{W}_{\mathrm{V}}$ were expressed in percent change from baseline and the comparison of the effect of each inhibitor on these variations was assessed using Wilcoxon matched-pairs signed rank test. A value of $p<0.05$ was considered statistically significant. 


\section{RESULTS}

\section{Comparison between HT and NT subjects at baseline}

At baseline there was no difference between NT and HT for demographic parameters. SBP, DBP, MBP, pulse pressure and heart rate were higher in HT than NT (Table 1). Ten subjects have a grade 1 hypertension and eight a grade 2 hypertension. There was no significant difference between groups for midwall stress and mean wall shear stress, characterizing respectively the baseline operating conditions and endothelial flow stimulus. In these conditions, $\mathrm{W}_{\mathrm{V}}$ was higher in HT than NT. This increase in $\mathrm{W}_{\mathrm{V}}$ was associated with a parallel increase in $\mathrm{W}_{\mathrm{E}}$ in $\mathrm{HT}$, resulting in a similar baseline $\mathrm{W}_{\mathrm{V}} / \mathrm{W}_{\mathrm{E}}$ ratio between groups (Table 2).

\section{Effect of increase in wall shear stress on AWV in NT and HT}

In saline conditions, hand skin heating resulted in a similar increase in mean wall shear stress in NT and HT without change in arterial pressure (Table 3). At the same time, midwall stress increased in both groups but to a larger extent in NT than in HT. In these conditions, $\mathrm{W}_{\mathrm{E}}$ and $\mathrm{W}_{\mathrm{V}}$ increased in both groups. However, in NT, the increases in $\mathrm{W}_{\mathrm{E}}$ and $\mathrm{W}_{\mathrm{V}}$ were similar (Table 3 ) resulting in a stable $\mathrm{W}_{\mathrm{V}} / \mathrm{W}_{\mathrm{E}}$ ratio (Figure $1 \mathrm{~A}$ ), whereas in $\mathrm{HT}, \mathrm{W}_{\mathrm{V}} / \mathrm{W}_{\mathrm{E}}$ increased (Figure $1 \mathrm{~A}$ ) due to a larger increase in $\mathrm{W}_{\mathrm{V}}$ than expected from the increase in $\mathrm{W}_{\mathrm{E}}$ (Table 3). These results suggest that an active mechanism prevents the increase in AWV in response to the flow-associated increase in midwall stress in NT and the loss of this mechanism in HT. 


\section{Role of NO and EETs in the regulation of AWV during increase in wall shear stress in NT and HT}

In all inhibition sequences, hand skin heating resulted in an increase in mean wall shear stress in both groups without change in arterial pressure (Table 3). The effect of inhibitors on change in $\mathrm{W}_{\mathrm{V}} / \mathrm{W}_{\mathrm{E}}$ ratio during the increase in mean wall shear stress was different between NT and HT ( $\mathrm{p}=0.02$ for the interaction between hypertension and sequences of inhibition), suggesting an impaired regulation of AWV by endothelial factors during hypertension.

In NT, the increase in mean wall shear stress is associated with an increase in $\mathrm{W}_{\mathrm{V}} / \mathrm{W}_{\mathrm{E}}$ after fluconazole, L-NMMA and their combination (Figures 1B-D). This effect was explained by a larger increase in $\mathrm{W}_{\mathrm{V}}$ than $\mathrm{W}_{\mathrm{E}}$ (Table 3). All these results were obtained despite a lower increase in midwall stress during heating in presence of the inhibitors compared to saline, particularly with L-NMMA and L-NMMA+fluconazole (Table 3). This demonstrates the role of NO and EETs in the regulation of AWV during the increase in flow in NT.

In $\mathrm{HT}$, the $\mathrm{W}_{\mathrm{V}} / \mathrm{W}_{\mathrm{E}}$ increased in all inhibition sequences (Figures 1B-D), because of a larger increase in $\mathrm{W}_{\mathrm{V}}$ than $\mathrm{W}_{\mathrm{E}}$ (Table 3 ). The magnitude of the increase in $\mathrm{W}_{\mathrm{V}} / \mathrm{W}_{\mathrm{E}}$ with all inhibitors was similar than during saline infusion, suggesting the absence of involvement of endothelial factors in the regulation of AWV in HT. However, while the increase in midwall stress was not modified by fluconazole as compared to saline, it was reduced by L-NMMA and L-NMMA+fluconazole (Table 3). The similar increase in $\mathrm{W}_{\mathrm{V}} / \mathrm{W}_{\mathrm{E}}$ despite the lower increase in midwall stress with NO-synthase inhibition suggests that a residual release of $\mathrm{NO}$ partially opposes the increase in $\mathrm{W}_{\mathrm{V}} / \mathrm{W}_{\mathrm{E}}$ related to the increase in midwall stress in HT. Conversely, the similar change in $\mathrm{W}_{\mathrm{V}} / \mathrm{W}_{\mathrm{E}}$ and 
midwall stress in saline and fluconazole conditions suggests the absence of EETs release after blood flow increase during hypertension. 


\section{DISCUSSION}

Our results demonstrate that NO and EETs maintain a stable AWV during flow increase in NT and that this regulation is altered in HT due to a larger increase in viscous than elastic work. Excessive loss of energy may contribute to impair cardiovascular coupling during hypertension in situation of increase in flow [5,25-27].

The study was performed in hypertensive patients and normotensive controls at the level of the radial artery to assess in vivo the endothelium-mediated flow-dependent regulation of the viscous behavior of peripheral conduit arteries and the impact of essential hypertension on this regulation. Untreated HT and NT were frequencymatched for the main cardiovascular risk factors to suppress their confounding effect. Viscous behavior of the radial artery was evaluated using a thermodynamic approach by measuring the hysteresis loop of the pressure-diameter relationship obtained using validated high-resolution echo-tracking methods $[1,4,8,17,28,29]$. Pressure and diameter waves were thus precisely synchronized on the foot of each wave resulting in the alignment of the upshot of the pressure and diameter pulses [23,30]. This step of synchronization is crucial and manually realized because it has been previously demonstrated that a little misalignment of the two waveforms, i.e. secondary to the different location of pressure and diameter measurements, could be responsible for an overestimation of the AWV [30]. Moreover, this approach was used to analyze the viscosity phenomenon as the source of energy dissipated by the arterial wall considering the energy delivered during the cardiac cycle [19,20,22]. Thus, in addition to the measurement of the area of the hysteresis loop corresponding to the energy dissipated during the cardiac cycle, we measured $\mathrm{W}_{\mathrm{E}}$ as specified in the methods section to express 
arterial viscous behavior as the absolute value of $\mathrm{W}_{\mathrm{V}}$ and as relative to one of its main determinant $\mathrm{W}_{\mathrm{E}}[1,4,19]$. These parameters were obtained at baseline and after the increase in forearm blood flow induced by using the hand skin heating method that enable to calculate the mean arterial wall shear stress at different flow level and to compare the flow-dependent response between hypertensive patients and control subjects [3]. Furthermore, we infused pharmacological inhibitors of NO and EETs synthesis to evaluate the role of the endothelium in the flow-dependent regulation of viscous behavior of the radial artery $[1,16]$. Thus, it was possible to evaluate the effect of endothelial factors on absolute and relative viscosity in absence of systemic effect and to consider simultaneous changes in arterial midwall stress, another major determinant of AWV [11,31].

In these conditions, in accordance with previous data obtained at the level of the carotid artery and the thoracic aorta by using different methods, including time domain analysis, the radial artery $\mathrm{W}_{\mathrm{V}}$ was increased in HT as compared with NT [24,32,33]. As previously stressed, this phenomenon is probably partly related to the vascular smooth muscle cells hypertrophy associated to the adaptive intima-media thickening to prevent the increase in midwall stress [34]. However, $\mathrm{W}_{\mathrm{E}}$ was also increased in relation with the increased PP in HT patients, resulting in a stable $\mathrm{W}_{\mathrm{V}} / \mathrm{W}_{\mathrm{E}}$ and supporting an effective adaptive process at rest [34].

During the hand skin heating, we observed for the first time in vivo, a different viscous response to the increase in arterial blood flow between NT and HT. Thus, under saline condition, there was no significant change in $\mathrm{W}_{\mathrm{V}} / \mathrm{W}_{\mathrm{E}}$ in $\mathrm{NT}$, due to a similar increase in $\mathrm{W}_{\mathrm{V}}$ and $\mathrm{W}_{\mathrm{E}}$, whereas $\mathrm{W}_{\mathrm{V}} / \mathrm{W}_{\mathrm{E}}$ increased in $\mathrm{HT}$, due to a larger increase in $\mathrm{W}_{\mathrm{V}}$ than $\mathrm{W}_{\mathrm{E}}$. The increase in blood flow in NT is known to be associated with the release of 
endothelial-derived relaxing factors responsible for the increase in radial artery diameter, i.e. flow-mediated dilation, and midwall stress and for the decrease in isometric vascular smooth muscle tone $[6,11,35]$. In HT, the endothelial dysfunction is associated with an impairment of endothelial factors release. Thus, during flow stimulation, the magnitude of the increase in pulse diameter at stable pulse pressure determined the magnitude of the increase in the area under pressure-diameter relationship during the loading phase, explaining the increase in $\mathrm{W}_{\mathrm{E}}$ in $\mathrm{NT}$ and the reduction of this increase in HT. This phenomenon corresponds to an increase in the energy mobilized during the increase in flow. In parallel, the increase in $W_{V}$ is explained by the close relationship between $\mathrm{W}_{\mathrm{E}}$ and $\mathrm{W}_{\mathrm{V}}$ and the dependence of $\mathrm{W}_{\mathrm{V}}$ to midwall stress, which is a major determinant of the viscous behavior $[24,36]$. However, in the present work we observed a larger increase in $\mathrm{W}_{\mathrm{V}}$ than $\mathrm{W}_{\mathrm{E}}$ in $\mathrm{HT}$ than in NT, despite the lower increase in midwall stress, suggesting that the relationship between $\mathrm{W}_{\mathrm{E}}$ and $\mathrm{W}_{\mathrm{V}}$ is different. Thus, in addition to $\mathrm{W}_{\mathrm{E}}$ and midwall stress, a third mechanism is involved in the adaptation of $\mathrm{W}_{\mathrm{V}} / \mathrm{W}_{\mathrm{E}}$ to flow increase. Consequently, we showed the role of NO and EETs in the regulation of AWV during increase in flow in NT. Indeed, L-NMMA and/or fluconazole infusion resulted in an increase in AWV despite a lower increase in midwall stress than during saline conditions. This result argues for a physiological balance between the increasing effect of midwall stress and the decreasing effect of the release of EETs and NO on AWV during increase in blood flow. To note, the absence of additive effect of the combined inhibition as compared to each inhibitor alone may result from the marked reduction in the increase in midwall stress, explaining an attenuated increase in $\mathrm{W}_{\mathrm{V}} / \mathrm{W}_{\mathrm{E}}$ compared to that expected from the disappearance of endothelial factors. 
In $\mathrm{HT}$, the increase in $\mathrm{W}_{\mathrm{V}} / \mathrm{W}_{\mathrm{E}}$ induced by heating was similar during saline and all inhibition conditions. For fluconazole, this was observed in presence of similar increase in midwall stress than during saline infusion, demonstrating the loss of EETs influence on AWV during HT. In fact, this result is in accordance with our previous findings in HT showing, using a biological approach, the abolition of EETs release during flow stimulation [16]. Conversely, there was a lesser increase in midwall stress with LNMMA alone and combined with fluconazole compared to saline during heating, and this should have been associated with a lesser increase in $\mathrm{W}_{\mathrm{V}} / \mathrm{W}_{\mathrm{E}}$. In fact, the higher increase in $\mathrm{W}_{\mathrm{V}} / \mathrm{W}_{\mathrm{E}}$ relative to midwall stress after NO-synthase inhibition confirms that a residual release of $\mathrm{NO}$ during flow stimulation occurs in $\mathrm{HT}$, allowing to partially oppose the increase in AWV [6,7].

This excessive energy loss in HT patients could promote an increase in cardiac work and cardiovascular uncoupling but also could accelerate degenerative process thus, contributing to the development of arteriosclerosis.

In this context, it remains to be carefully investigated whether the correction of endothelial dysfunction restores a normal AWV. In particular, the restoration of NO bioavailability using angiotensin-converting enzyme (ACE) inhibitors is associated with positive effects on endothelial dysfunction and arterial stiffness in human hypertension, but little information is available regarding AWV [7,37]. Only one previous study reported a parallel decrease in viscous and elastic works after ACE inhibition in HT patients at baseline, with a stable ratio [24]. However, even when blood pressure is normalized with conventional antihypertensive agents, third of the patients still have a persistent endothelial dysfunction that hampers the prognosis of patients [38]. In this context, the restoration of EETs bioavailability using inhibitors of their degradation by 
soluble epoxide hydrolase inhibitors may be of particular interest. These agents have been shown to correct endothelial dysfunction in animal models of reno-vascular hypertension and some of them entered the first phases of clinical development $[39,40]$. These inhibitors constitute a new promising pharmacological class to finally prevent endothelial dysfunction and to improve arterial mechanics in particular allowing the reduction of AWV

In conclusion, these results demonstrate for the first time in humans that endothelialderived NO and EETs contribute to maintain a stable AWV of peripheral conduit arteries during the increase in blood flow in physiological conditions and that this regulatory mechanism is impaired in HT. The pharmacological correction of these abnormalities could be of interest to improve the cardiovascular prognosis of patients with HT. 


\section{CONFLICT OF INTEREST}

The authors declared they do not have anything to disclose regarding conflict of interest with respect to this manuscript.

\section{FINANCIAL SUPPORT}

This study was supported by grants from the Sociéte Française d'Hypertension Artérielle and from the Institut National de la Santé et de la Recherche Médicale (Inserm).

\section{AUTHOR CONTRIBUTIONS}

F.R. and R.J. contribute to the design of the study, data management, writing and reviewing process, J.B contribute to the design of the study, acquisition of data, writing and reviewing process, M.I. contribute to the design of the study, acquisition of data and reviewing process.

\section{ACKNOWLEDGEMENTS}

The authors thank Laurence Gutierrez (Clinical Investigation Center CIC-CRB 1404, Rouen University Hospital, Rouen, Normandie, France) for her technical assistance. 


\section{REFERENCES}

1 Roca F, Iacob M, Remy-Jouet I, Bellien J, Joannides R. Evidence for a Role of Vascular Endothelium in the Control of Arterial Wall Viscosity in Humans. Hypertension 2018; $71: 143-150$.

2 Busse R, Bauer RD, Sattler T, Schabert A. Dependence of elastic and viscous properties of elastic arteries on circumferential wall stress at two different smooth muscle tones. Pflugers Arch 1981; 390:113-119.

3 Bergel DH. The dynamic elastic properties of the arterial wall. J Physiol 1961; $156: 458-469$.

4 Boutouyrie P, Boumaza S, Challande P, Lacolley P, Laurent S. Smooth muscle tone and arterial wall viscosity: an in vivo/in vitro study. Hypertension 1998; 32:360-364.

5 Cusmà Piccione M, Zito C, Khandheria B, Madaffari A, Oteri A, Falanga G, et al. Cardiovascular maladaptation to exercise in young hypertensive patients. Int J Cardiol $2017 ; 232: 280-288$.

6 Bellien J, Iacob M, Remy-Jouet I, Lucas D, Monteil C, Gutierrez L, et al. Epoxyeicosatrienoic acids contribute with altered nitric oxide and endothelin-1 pathways to conduit artery endothelial dysfunction in essential hypertension. Circulation 2012; 125:1266-1275.

7 Ghiadoni L, Versari D, Magagna A, Kardasz I, Plantinga Y, Giannarelli C, et al. Ramipril dose-dependently increases nitric oxide availability in the radial artery of essential hypertension patients. Journal of Hypertension 2007; 25:361-366. 
8 Joannides R, Richard V, Moore N, Godin M, Thuillez C. Influence of sympathetic tone on mechanical properties of muscular arteries in humans. Am J Physiol 1995; 268:H794-H801.

9 Bellien J, Favre J, Iacob M, Gao J, Thuillez C, Richard V, et al. Arterial stiffness is regulated by nitric oxide and endothelium-derived hyperpolarizing factor during changes in blood flow in humans. Hypertension 2010; 55:674-680.

10 Parati G, Casadei R, Groppelli A, Rienzo MD, Mancia G. Comparison of finger and intra-arterial blood pressure monitoring at rest and during laboratory testing. Hypertension 1989; 13:647-655.

11 Joannides R, Richard V, Haefeli WE, Benoist A, Linder L, Lüscher TF, et al. Role of Nitric Oxide in the Regulation of the Mechanical Properties of Peripheral Conduit Arteries in Humans. Hypertension 1997; 30:1465-1470.

12 Chowienczyk PJ, Kelly RP, MacCallum H, Millasseau SC, Andersson TLG, Gosling RG, et al. Photoplethysmographic assessment of pulse wave reflection. Journal of the American College of Cardiology 1999; 34:2007-2014.

13 Millasseau SC, Guigui FG, Kelly RP, Prasad K, Cockcroft JR, Ritter JM, et al. Noninvasive Assessment of the Digital Volume Pulse. Hypertension 2000; 36:952-956.

14 Millasseau SC, Ritter JM, Takazawa K, Chowienczyk PJ. Contour analysis of the photoplethysmographic pulse measured at the finger. J Hypertens 2006; 24:1449-1456.

15 Nichols W, O'Rourke M, Vlachopoulos C. McDonald's Blood Flow in Arteries, Sixth Edition: Theoretical, Experimental and Clinical Principles. CRC Press; 2011.

16 Bellien J, Remy-Jouet I, Iacob M, Blot E, Mercier A, Lucas D, et al. Impaired role of epoxyeicosatrienoic acids in the regulation of basal conduit artery diameter during essential hypertension. Hypertension 2012; 60:1415-1421. 
17 Bellien J, Joannides R, Iacob M, Arnaud P, Thuillez C. Calcium-Activated Potassium Channels and NO Regulate Human Peripheral Conduit Artery Mechanics. Hypertension $2005 ; 46: 210-216$.

18 Bellien J, Iacob M, Gutierrez L, Isabelle M, Lahary A, Thuillez C, et al. Crucial Role of NO and Endothelium-Derived Hyperpolarizing Factor in Human Sustained Conduit Artery Flow-Mediated Dilatation. Hypertension 2006; 48:1088-1094.

19 Boutouyrie P, Bézie Y, Lacolley P, Challande P, Chamiot-Clerc P, Benetos A, et al. In vivo/in vitro comparison of rat abdominal aorta wall viscosity. Influence of endothelial function. Arterioscler Thromb Vasc Biol 1997; 17:1346-1355.

20 Bertram CD. Energy dissipation and pulse wave attenuation in the canine carotid artery. J Biomech 1980; 13:1061-1073.

21 Shau YW, Wang CL, Shieh JY, Hsu TC. Noninvasive assessment of the viscoelasticity of peripheral arteries. Ultrasound Med Biol 1999; 25:1377-1388.

22 Alexander RM. Animal mechanics. Blackwell Scientific; 1983.

23 Lénárd Z, Fülöp D, Visontai Z, Jokkel G, Reneman R, Kollai M. Static versus dynamic distensibility of the carotid artery in humans. J Vasc Res 2000; 37:103-111.

24 Armentano RL, Barra JG, Santana DB, Pessana FM, Graf S, Craiem D, et al. Smart damping modulation of carotid wall energetics in human hypertension: effects of angiotensin-converting enzyme inhibition. Hypertension 2006; 47:384-390.

25 Mitchell JH. Abnormal cardiovascular response to exercise in hypertension: contribution of neural factors. Am J Physiol Regul Integr Comp Physiol 2017; 312:R851-R863.

26 Shim CY, Park S, Choi E-Y, Hong G-R, Choi D, Jang Y, et al. The relationship between ventricular-vascular uncoupling during exercise and impaired left ventricular 
longitudinal functional reserve in hypertensive patients. J Am Soc Hypertens 2013; $7: 198-205$.

27 Nitenberg A, Loiseau A, Antony I. Left ventricular mechanical efficiency in hypertensive patients with and without increased myocardial mass and with normal pump function. Am J Hypertens 2001; 14:1231-1238.

28 Tardy Y, Meister JJ, Perret F, Brunner HR, Arditi M. Non-invasive estimate of the mechanical properties of peripheral arteries from ultrasonic and photoplethysmographic measurements. Clin Phys Physiol Meas 1991; 12:39.

29 Laurent S, Girerd X, Mourad JJ, Lacolley P, Beck L, Boutouyrie P, et al. Elastic modulus of the radial artery wall material is not increased in patients with essential hypertension. Arterioscler Thromb Vasc Biol 1994; 14:1223-1231.

30 Hoeks AP, Willigers JM, Reneman RS. Effects of assessment and processing techniques on the shape of arterial pressure-distension loops. J Vasc Res 2000; 37:494500.

31 Bellien J, Joannides R, Iacob M, Arnaud P, Thuillez C. Evidence for a basal release of a cytochrome-related endothelium-derived hyperpolarizing factor in the radial artery in humans. Am J Physiol Heart Circ Physiol 2006; 290:H1347-H1352.

32 Armentano R, Megnien JL, Simon A, Bellenfant F, Barra J, Levenson J. Effects of hypertension on viscoelasticity of carotid and femoral arteries in humans. Hypertension $1995 ; 26: 48-54$

33 Stefanadis C, Dernellis J, Vlachopoulos C, Tsioufis C, Tsiamis E, Toutouzas K, et al. Aortic Function in Arterial Hypertension Determined by Pressure-Diameter Relation Effects of Diltiazem. Circulation 1997; 96:1853-1858. 
34 Armentano RL, Graf S, Barra JG, Velikovsky G, Baglivo H, Sánchez R, et al. Carotid wall viscosity increase is related to intima-media thickening in hypertensive patients. Hypertension 1998; 31:534-539.

35 Green DJ, Dawson EA, Groenewoud HMM, Jones H, Thijssen DHJ. Is flow-mediated dilation nitric oxide mediated?: A meta-analysis. Hypertension 2014; 63:376-382.

36 Orban F. Damping of materials and members in structures. J Phys: Conf Ser 2011; 268:012022.

37 Cameron AC, Lang NN, Touyz RM. Drug Treatment of Hypertension: Focus on Vascular Health. Drugs 2016; 76:1529-1550.

38 Modena MG, Bonetti L, Coppi F, Bursi F, Rossi R. Prognostic role of reversible endothelial dysfunction in hypertensive postmenopausal women. Journal of the American College of Cardiology 2002; 40:505-510.

39 Gao J, Bellien J, Gomez E, Henry J-P, Dautreaux B, Bounoure F, et al. Soluble epoxide hydrolase inhibition prevents coronary endothelial dysfunction in mice with renovascular hypertension. J Hypertens 2011; 29:1128-1135.

40 Lazaar AL, Yang L, Boardley RL, Goyal NS, Robertson J, Baldwin SJ, et al. Pharmacokinetics, pharmacodynamics and adverse event profile of GSK2256294, a novel soluble epoxide hydrolase inhibitor. Br J Clin Pharmacol 2016; 81:971-979. 


\section{Figure legend:}

Figure 1: Effect of hand skin heating on $\mathrm{W}_{\mathrm{V}} / \mathrm{W}_{\mathrm{E}}$ ratio obtained at $34^{\circ} \mathrm{C}(\square)$ and $44^{\circ} \mathrm{C}$ (匹), under saline (A), fluconazole (B), L-NMMA (C) and L-NMMA+fluconazole (D) conditions.

NT: Normotensive controls; HT: Hypertensive patients. ${ }^{*} p<0.05$ vs. $34^{\circ} \mathrm{C}, \S p<0.05$ vs. NT, $\dagger p<0.05$ vs. saline. 
A $\quad$ Saline

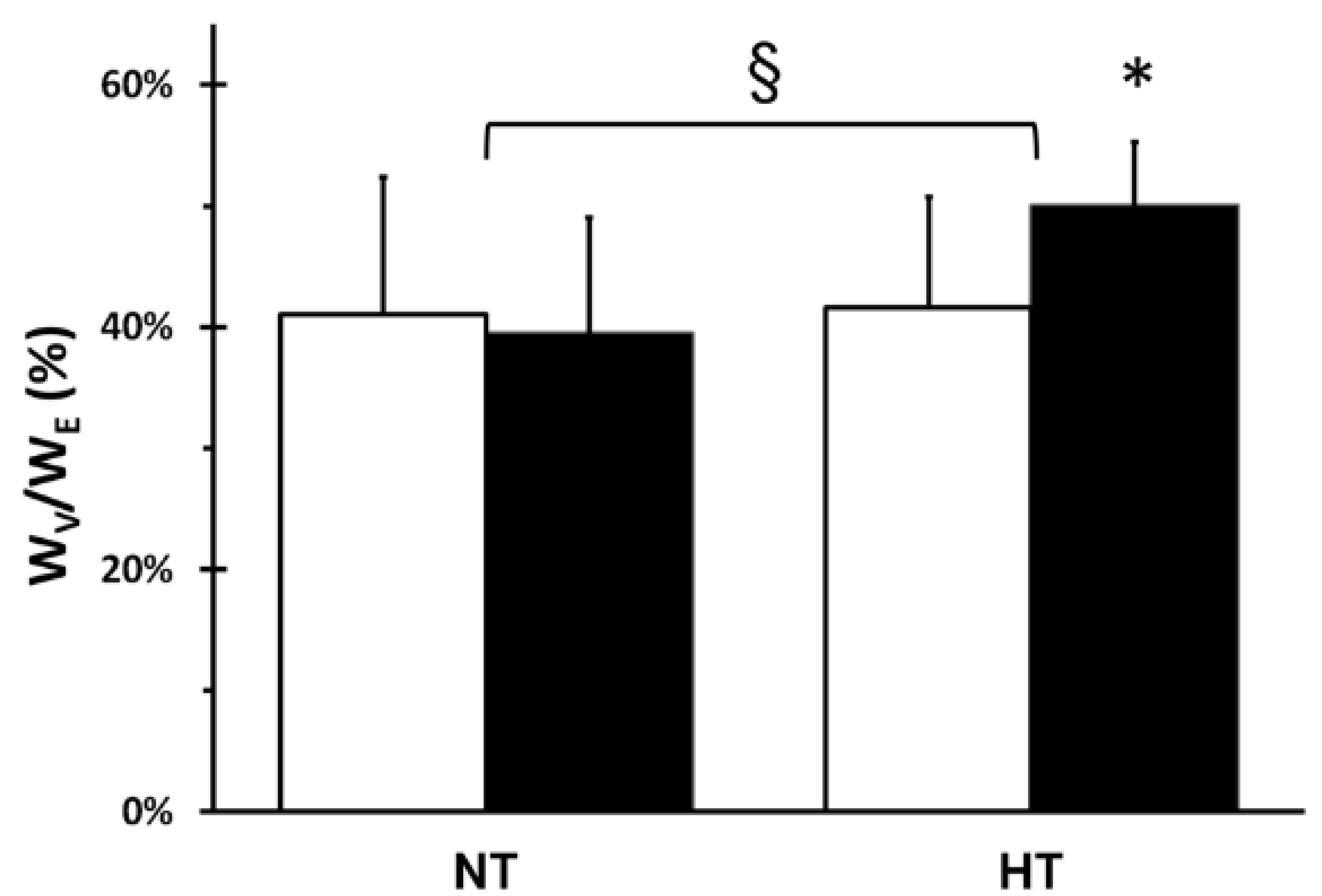

\section{C}

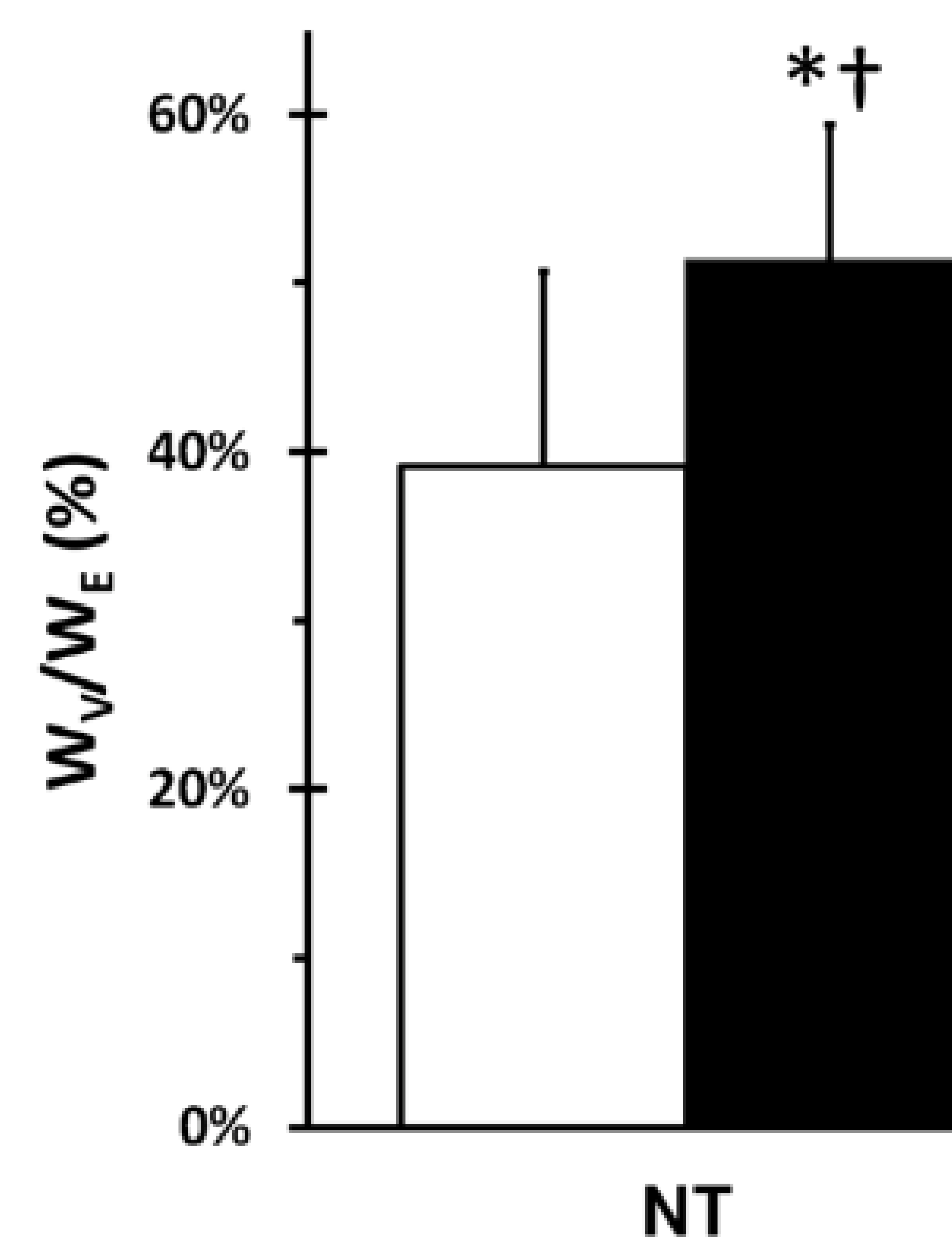

L-NMMA

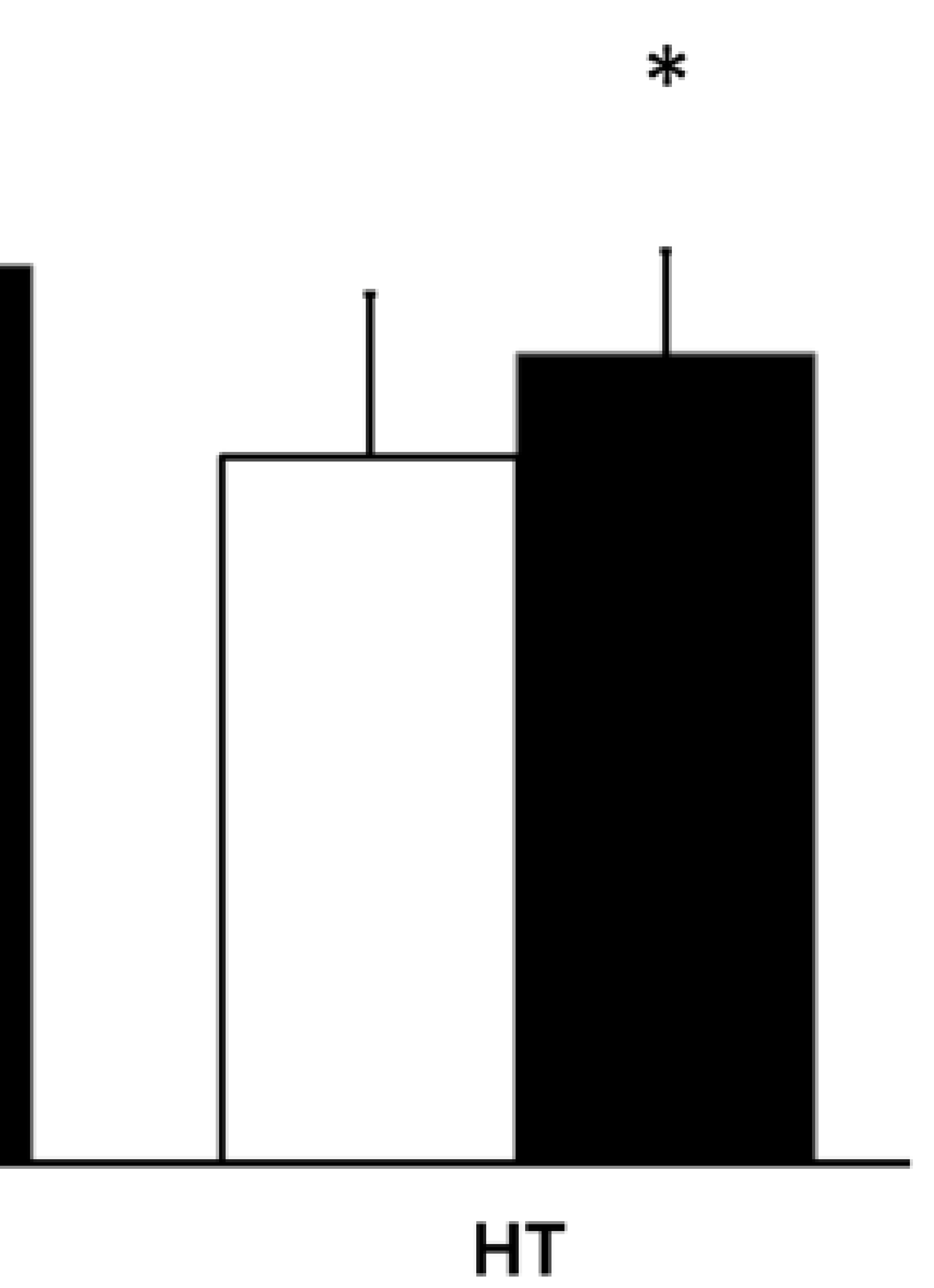

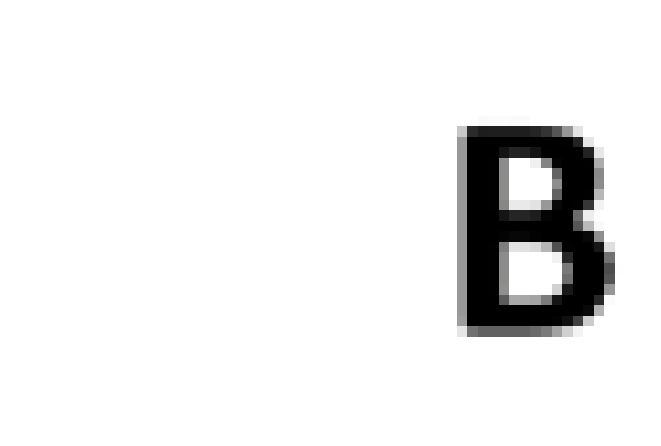

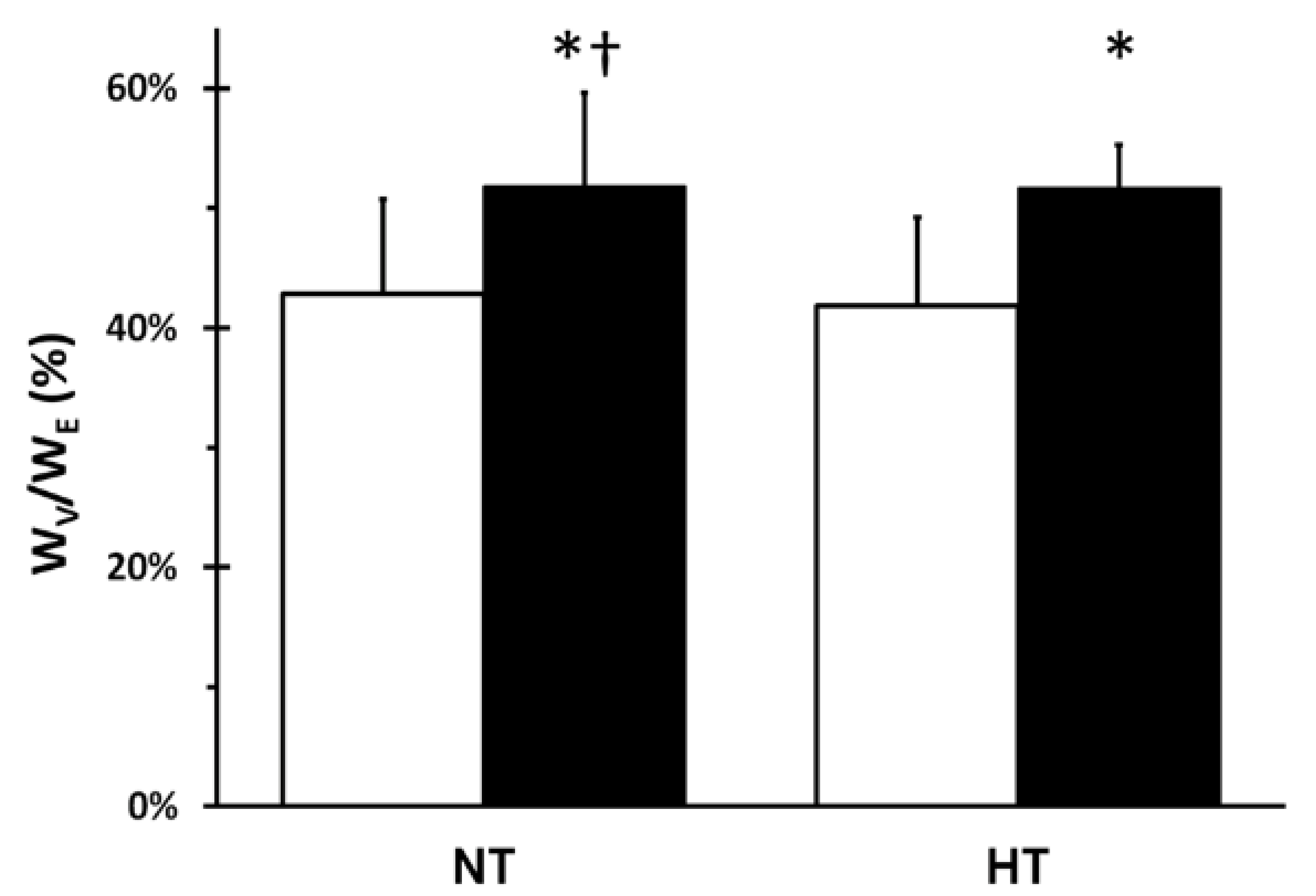

D

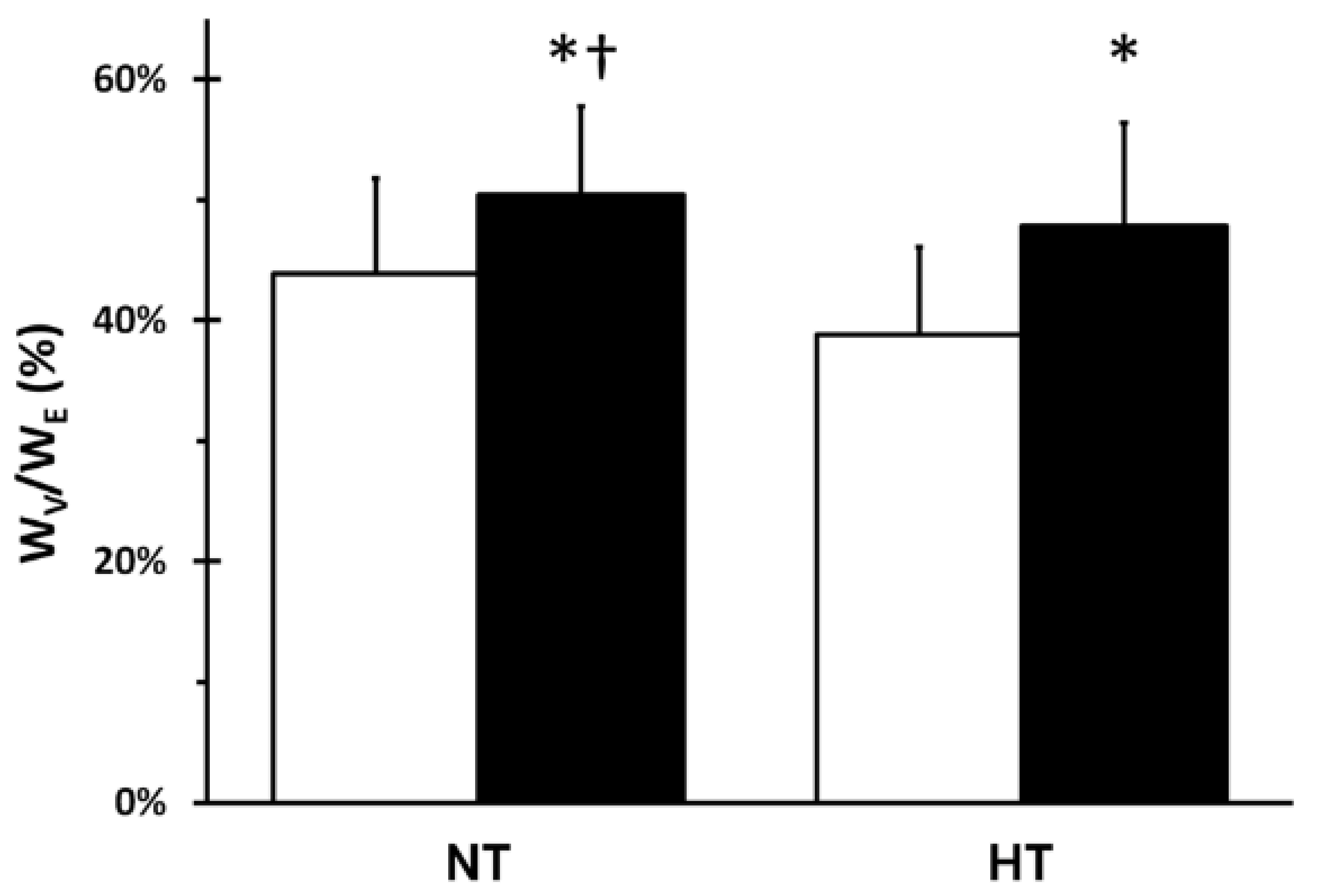


Table 1. Baseline characteristics of normotensive controls and hypertensive patients.

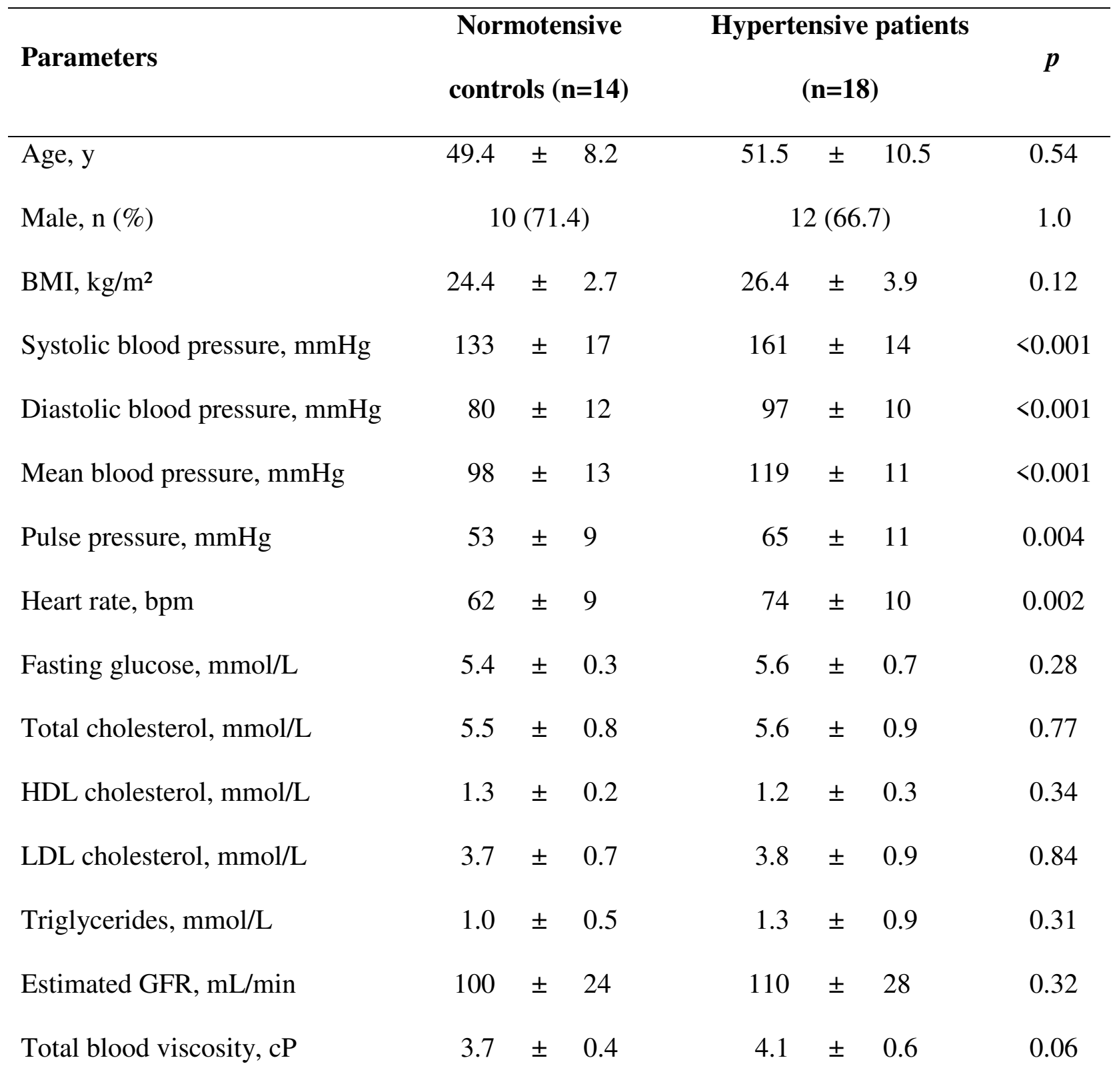

BMI: Body mass index; HDL: High density lipoprotein; LDL: Low density lipoprotein; GFR:

Glomerular filtration rate.

$* p<0.05$ versus Normotensive controls 
Table 2. Baseline radial artery parameters in normotensive controls and hypertensive patients.

\begin{tabular}{|c|c|c|c|}
\hline Parameters & $\begin{array}{l}\text { Normotensive } \\
\text { controls }(n=14)\end{array}$ & $\begin{array}{c}\text { Hypertensive } \\
\text { patients }(n=18)\end{array}$ & $p$ \\
\hline Radius to wall thickness ratio & $6.2 \pm 1.0$ & $5.0 \pm 0.5$ & $<0.001$ \\
\hline $\begin{array}{l}\text { Radial artery mean wall shear } \\
\text { stress, } 10^{-1} \mathrm{~Pa}\end{array}$ & $3.9 \pm 2.7$ & $4.2 \pm 2.3$ & 0.70 \\
\hline Midwall stress, $10^{1} \mathrm{kPa}$ & $7.3 \pm 1.7$ & $6.9 \pm 0.8$ & 0.35 \\
\hline $\mathrm{W}_{\mathrm{V}}, 10^{-2} \mathrm{~J} / \mathrm{m}^{2}$ & $7.3 \pm 4.1$ & $12.0 \pm 6.2$ & 0.03 \\
\hline $\mathrm{W}_{\mathrm{E}}, 10^{-2} \mathrm{~J} / \mathrm{m}^{2}$ & $18.3 \pm 9.2$ & $28.3 \pm 12.0$ & 0.02 \\
\hline $\mathrm{W}_{\mathrm{V}} / \mathrm{W}_{\mathrm{E}}, \%$ & $40.2 \pm 5.9$ & $40.3 \pm 7.1$ & 0.95 \\
\hline
\end{tabular}


Table 3. Variations of the radial artery parameters during hand skin heating in presence of saline, fluconazole, L-NMMA and LNMMA+fluconazole in normotensive controls and hypertensive patients

\begin{tabular}{|c|c|c|c|c|c|c|c|c|}
\hline \multirow[t]{2}{*}{ Parameters } & \multicolumn{2}{|c|}{ Saline } & \multicolumn{2}{|c|}{ Fluconazole } & \multicolumn{2}{|c|}{ L-NMMA } & \multicolumn{2}{|c|}{ L-NMMA+fluconazole } \\
\hline & NT & HT & NT & HT & NT & HT & NT & HT \\
\hline$\Delta \mathrm{MBP}, \mathrm{mmHg}$ & $1.4 \pm 8.9$ & $-1.5 \pm 11.3$ & $1 \pm 8$ & $3.4 \pm 15.7$ & $7.4 \pm 10.2$ & $3.9 \pm 7.6$ & $3.2 \pm 9.8$ & $3.8 \pm 7.3$ \\
\hline$\Delta \mathrm{PP}, \mathrm{mmHg}$ & $-0.6 \pm 10.9$ & $-1.6 \pm 9.4$ & $-0.1 \pm 7.5$ & $-1.3 \pm 13.4$ & $2.1 \pm 11.1$ & $1.8 \pm 6.3$ & $1.2 \pm 10.9$ & $2.8 \pm 10.6$ \\
\hline$\Delta \mathrm{R} / \mathrm{h}$ & $2.0 \pm 1.0^{*}$ & $1.3 \pm 0.9 * \S$ & $1.3 \pm 0.4 * \dagger$ & $1.1 \pm 0.6^{*}$ & $0.9 \pm 0.7 * \dagger$ & $0.7 \pm 0.8 * \dagger$ & $0.8 \pm 0.8^{*} \dagger$ & $0.3 \pm 0.6 \dagger$ \\
\hline$\Delta \mathrm{MWSS}, 10^{-1} \mathrm{~Pa}$ & $12.1 \pm 7.4^{*}$ & $12.9 \pm 9.4^{*}$ & $10.1 \pm 6.6^{*}$ & $9.8 \pm 8.1 *$ & $14.7 \pm 12.8^{*}$ & $9.0 \pm 6.5^{*}$ & $9.4 \pm 7.9 *$ & $12.3 \pm 9.1^{*}$ \\
\hline$\Delta \sigma, 10^{1} \mathrm{kPa}$ & $2.7 \pm 0.8 *$ & $1.8 \pm 1.4 * \S$ & $1.9 \pm 0.4 * \dagger$ & $2 \pm 1.1 *$ & $1.8 \pm 1.3 * \dagger+$ & $1.1 \pm 1.1 * \dagger+$ & $1.4 \pm 0.9 * \dagger+$ & $0.7 \pm 1.3 \dagger+$ \\
\hline $\begin{array}{l}\Delta \mathrm{W}_{\mathrm{v}}, \% \text { change } \\
\text { from baseline }\end{array}$ & $37[-26,55]^{*}$ & $54[32,60]^{*}$ & $47[19,50]^{*}$ & $42[33,51]^{*} \|$ & $75[66,170]^{*}$ & $50[34,83]^{*}$ & $35[16,107]^{*}$ & $82[6,303]^{*} \|$ \\
\hline $\begin{array}{l}\Delta \mathrm{W}_{\mathrm{E}}, \% \text { change } \\
\text { from baseline }\end{array}$ & $26[-25,50]^{*}$ & $37[9,45]^{*}$ & $23[9,35]^{*}$ & $31[17,38]^{*}$ & $25[5,92]^{*}$ & $30[10,50]^{*}$ & $12[2,75]^{*}$ & $43[-6,192]^{*}$ \\
\hline
\end{tabular}

NT: Normotensive controls; HT: Hypertensive patients; MBP: Mean blood pressure; PP: Pulse pressure; R/h: Radius to wall thickness ratio; PD:

Pulse diameter; MWSS: Radial artery mean wall shear stress; $\sigma$ : Midwall stress; $\mathrm{W}_{\mathrm{V}}$ : Viscous energy; $\mathrm{W}_{\mathrm{E}}$ : Elastic energy. ${ }^{*} \mathrm{p}<0.05$ versus $34^{\circ} \mathrm{C}$,

$\dagger \mathrm{p}<0.05$ versus saline, $\ddagger \mathrm{p}<0.05$ versus fluconazole $; \S \mathrm{p}<0.05$ versus $\mathrm{NT} ; \| \mathrm{p}<0.05$ versus $\Delta \mathrm{W}_{\mathrm{E}}$ 
